\title{
Variantes del ADNmt en isleños del lago Titicaca: máxima frecuencia del haplotipo B1 y evidencia de efecto fundador
}

\section{Variants of mtDNA among islanders of the lake Titicaca: highest frequency of haplotype B1 and evidence of founder effect}

\author{
José Sandoval, Bedsabé Delgado, Luis Rivas, Bertha Bonilla, Daniel Nugent y \\ Ricardo Fujita*
}

Presentado: $23 / 07 / 2004$

Aceptado: $\quad 29 / 12 / 2004$

\section{Resumen}

Los polimorfismos del ADN mitocondrial son herramientas en el estudio comparativo de poblaciones modernas y antiguas. Entre los más usados están los haplotipos mitocondriales basados en RFLP (polimorfismo de longitud de fragmentos de restricción) y un sistema de inserción /deleción. El presente estudio establece la frecuencia de estos haplotipos y compara un total de 144 individuos representativos de las islas Taquile y Amantaní (lengua quechua) y de las islas de Los Uros y Anapia (lengua aymara) del lago Titicaca, Perú. Nuestros resultados revelan la predominancia del haplotipo B1: $100 \%$ en Taquile ( $n=57) ; 88,6 \%$ en Amantaní $(n=35) ; 75 \%$ en Los Uros $(n=28)$ y $87,5 \%$ en Anapia $(n=24)$, siendo las frecuencias más altas registradas en el mundo. Otros haplotipos se observan en menor proporción: $17,9 \%$ de A2 y 7,1\% de D1 en Los Uros; $11,4 \%$ de la variante C1 en Amantaní; 4,2\% de cada haplotipo C1, C2 y D1 en Anapia. La alta frecuencia de B1 indica que las poblaciones de Taquile, Amantaní y Anapia provienen de un grupo fundador reducido. Aunque hay afinidad entre las poblaciones aymaras de Anapia y Los Uros; la proporción de algunos alelos en los últimos, sugiere la persistencia de un acervo genético uru en contraposición a la idea de su extinción.

Palabras clave: ADN mitocondrial, isleños del Lago Titicaca, haplotipos, RFLP.

\section{Abstract}

We analyzed mitochondrial DNA haplotypes from 144 samples of islanders of the Taquile and Amantani (Quechua speakers) and Los Uros and Anapia (Aymara speakers) of the Lake Titicaca, Peru. We have found the highest frequency of B1 mtDNA haplotype ever reported: $100 \%$ in Taquile ( $\mathrm{n}=$ 57); $88,6 \%$ in Amantani ( $n=35) ; 87,5 \%$ in Anapia ( $n=24)$ and $75 \%$ in Los Uros $(n=28)$. There are other haplotypes but in low frequencies: $11,4 \%$ of $\mathrm{C} 1$ in Amantani; $17,9 \%$ of A2 and 7,1\% of D1 in Los Uros; $4,2 \%$ of $C 1, C 2$ and D1 haplotypes in Anapia. The high frequency of the B1 haplotype indicates that Taquile, Amantaní and Anapia islands have been populated by a reduced founder group. Although the genetic affinity between islanders of Anapia and Los Uros, the proportion of some alleles in the latter suggest the persistence of the uru genetic background.

Keywords: mitochondrial DNA, Lake Titicaca islanders, haplotypes, RFLP.

\section{Introducción}

La composición étnica en el Perú está formada por poblaciones de origen nativo, europeo, africano y asiático. En la actualidad se observa un mestizaje generalizado, sin embargo aún quedan algunas poblaciones homogé-

*) Instituto de Genética y Biología Molecular, Facultad de Medicina, Universidad de San Martín de Porres. Alameda del Corregidor Cdra. 15, La Molina, Lima, Perú.

Email: José Sandoval jsandoval@usmp.edu.pe

Ricardo Fujita rfujita@amauta.rcp.net.pe neas que posibilitan el estudio de sus orígenes. Las migraciones y el aislamiento geográfico a través de los siglos, han sido los factores determinantes en la variabilidad interpoblacional, así como en la homogeneidad genética dentro de cada una de ellas. El origen de muchas comunidades nativas actuales es desconocido y de ello solamente se cuentan con teorías basadas en sus tradiciones orales y crónicas o registros llevados por los conquistadores españoles a partir del siglo XVI (Bouysse-Cassagne, 1991). 
Actualmente, los pobladores peruanos de las islas del lago Titicaca y en general de la región del Collao, hablan quechua y aymara. Sin embargo, las crónicas de la conquista española y la colonia registraron además las lenguas uruquilla y puquina. En aquella época había un grupo humano denominado uru o huma haque (gente del agua) en aymara; ellos hablaban uruquilla y habitaban las orillas del lago Titicaca, dedicándose a actividades primarias como pesca, caza y recolección. Hasta el siglo XVI, los urus eran aproximadamente el $25 \%$ de la población del Collao. Se distribuían por un eje acuático formado por el río Azángaro, lago Titicaca, río Desaguadero en Perú; lago Poopó, río Lacajahuira y el lago Coipasa en Bolivia. Se sabe además, que en esta época habían pescadores urus en la jurisdicción de Arequipa, en el desierto de Atacama y en la costa de Arica e Iquique (Manelis de Klein, 1973; Wachtel, 1986).

Desde la época de la conquista hasta los tiempos actuales se ha percibido un descenso de la población $u r u$, e incluso hay investigadores que sugieren la casi desaparición de este grupo del territorio peruano (Manelis de Klein, 1973; Gran Enciclopedia del Perú, 1998). Otros autores sugieren que paulatinamente, los urus fueron asimilados por el sistema colonial y republicano perdiendo las características de su cultura, muchos de ellos «aymarizándose» (Wachtel, 1986). Estos antecedentes conllevan a pensar que los habitantes de las islas Los Uros mantendrían todavía parte de su acervo genético proveniente de los urus originales.

En otro caso, en las islas Taquile y Amantaní hay evidencias arqueológicas e históricas de poblamientos sucesivos desde épocas preincaicas, incaica y colonial. En ellas se han encontrado restos de la cultura Tiahuanaco; luego habitada por mitimaes durante el Tahuantinsuyo. Según las crónicas españolas, la península de Capachica, islas Amantaní, Titicaca (isla del Sol) y Coati (isla de la Luna) fueron ocupadas por los collas considerados «los tejedores del Inca» (BouysseCassagne, 1991) (precisamente, el arte textil es muy significativo en Taquile y Amantaní). Después de 1650 las islas Taquile y Amantaní fueron adquiridas por el encomendero español Pedro Gonzales de Taquila, trayendo consigo gente de lugares no determinados (Espinoza-Avendaño, 1989). Algunas crónicas relatan que Amantaní fue evacuada antes de ser repoblada por su hacendado; no hay referencia sobre Taquile, pero se asume que sufrió la misma suerte. En las tradiciones orales de los taquileños hay coincidencias sobre el hecho del repoblamiento, pero difieren en el grupo humano que lo hizo: i) original (antiguos isleños), ii) ribereños del lago, (EspinozaAvendaño, 1989; Bouysse-Cassagne, 1991). Taquile y Amantaní se mantuvieron relativamente aisladas hasta 1960 , por lo cual podemos asumir que la población es en su mayoría descendiente del repoblamiento del siglo XVII.

Por otro lado, en la isla Anapia-Suana (ubicada en el Lago Menor o Wiñaymarca) e islas cercanas como Suriki, Pariti, Anayutani, así como en Titicaca y Coati, también se han encontrado vestigios de las culturas Tiahuanaco e Incaica (Bouysse-Cassagne, 1991). Desde tiempos remotos los antiguos pobladores del lago Menor se dedicaban a la agricultura, ganadería y la pesca. En el siglo $\mathrm{XV}$, la mayor parte de esta región era habitada por los collas (de lengua aymara), quienes fueron sometidos por el Inca Pachacutec. Luego, en la época del colonialismo europeo, las islas de Wiñaymarca fueron utilizadas como haciendas españolas, y posteriormente devueltas a sus comunidades.

El parentesco genético puede ser determinado por el uso de polimorfismos de ADN estándar que permiten comparar datos obtenidos por diferentes grupos de investigadores (Merriwether et al., 1996; Simoni et al., 2000). Los polimorfismos de ADN más utilizados en estudios de poblaciones son los del ADN mitocondrial (ADNmt). Estos son revelados por la presencia o ausencia de sitios de restricción (RFLPs, polimorfismo de longitud de fragmentos de restricción) específicos en varios puntos del ADNmt y por la inserción/ 


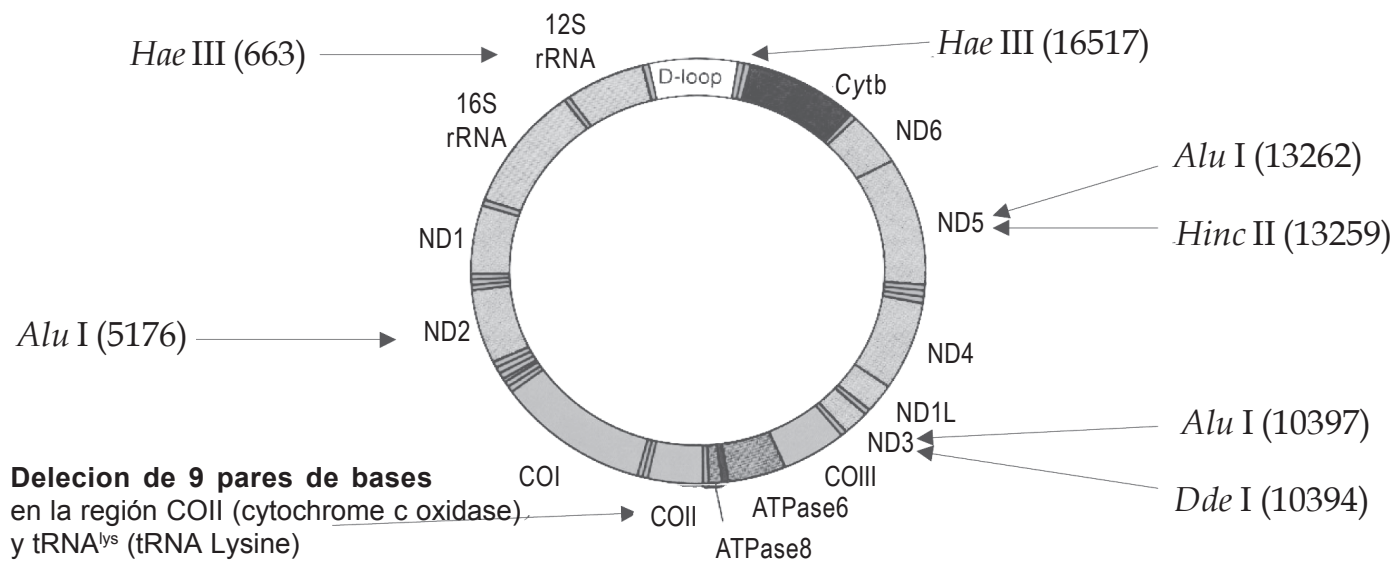

Figura 1. Sitios polimórficos (RFLPs con sus respectivas enzimas de restricción) que se analizan para determinar las variantes DNA mitocondriales de poblaciones asiáticas y amerindias.

deleción de 9 pares de nucleótidos (Fig. 1,2 y 3). Otras variantes son detectadas sólo con el secuenciamiento directo en la región D-loop (Stone \& Stoneking, 1998).

En la mayoría de los ADN mitocondriales de las poblaciones nativas americanas prevalecen 8 haplotipos: $A 1, A 2, B 1, B 2, C 1, C 2$, $D 1$ y $D 2$ del genoma mitocondrial. La frecuencia de cada tipo varía en las diferentes poblaciones; siendo B (B1) el más frecuente entre los quechuas y aymaras, asi como en un estudio de otros nativos peruanos (Merriwether et al., 1996; Rodríguez-Delfín et al., 2001).
En el presente trabajo se analizan los haplotipos mitocondriales de poblaciones nativas del lago Titicaca y se da una interpretación de las relaciones entre éstas.

\section{Materiales y métodos}

Luego del apropiado consentimiento, se obtuvo muestras de sangre de un total de 151 individuos voluntarios de 10 a 18 años de edad de cuatro islas del lago Titicaca. El muestreo sanguíneo se efectuó a fines de 1998. Diecinueve muestras del Centro Educativo Particular (C.E.P.) 70682 «Uros Torani Pata», 9 muestras del Centro Educativo Superior

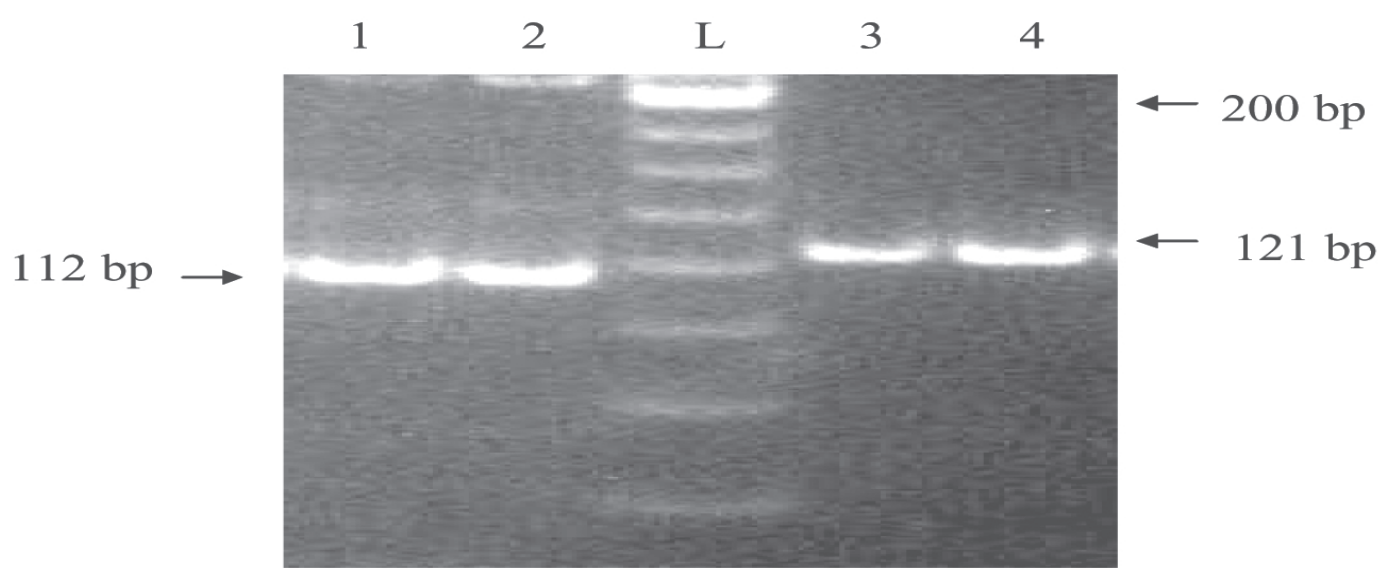

Figura 2. Polimorfismo de la deleción $9 \mathrm{pb}$ en el ADN mitocondrial, observado en gel-electroforesis (poliacrilamida $4 \%$ ) / EtBr. 1 y 2 = del 9 pb; 3 y 4 = no del 9 bp; L = escala de 20 pb. 
Tabla 1. Distribución de frecuencias (porcentajes) de los subtipos de los haplogrupos mtDNA $A, B, C$ y $D$, en cuatro poblaciones humanas del lago Titicaca. $h=$ índice de su diversidad genética, $\mathrm{n}=$ número de individuos.

\begin{tabular}{lcccccccccc}
\hline Población & $\mathbf{n}$ & A1 & A2 & B1 & B2 & C1 & C2 & D1 & D2 & $\boldsymbol{h}^{\text {* }}$ \\
\hline Los Uros & 28 & 0 & 17,9 & 75 & 0 & 0 & 0 & 7,1 & 0 & 0,415 \\
Anapia & 24 & 0 & 0 & 87,5 & 0 & 4,2 & 4,2 & 4,2 & 0 & 0,239 \\
Amantaní & 35 & 0 & 0 & 88,6 & 0 & 11,4 & 0 & 0 & 0 & 0,208 \\
Taquile & 57 & 0 & 0 & 100 & 0 & 0 & 0 & 0 & 0 & 0 \\
\hline
\end{tabular}

(C.E.S.) Técnico Artesanal «Uros Chulluni»; 41 muestras del C.E.S. Artesanal Taquile, 20 muestras de la Escuela Particular Nuestra Señora de Los Campos-Taquile, 23 muestras del C.E.S. Agro Artesanal «Miguel Grau» Amantaní, 13 muestras del C.E.P. 70037 Amantaní; y 26 muestras del C.E.S. Anapia. La sangre fue guardada en congelación para su transporte y conservación.
La extracción de ADN de las muestras de sangre congelada se efectuó por una técnica simplificada sin fenol-cloroformo (Fujita, 1991). La reacción de amplificación PCR (polymerase chain reaction) se realizó en microtubos dentro del termociclador Thermolyne Amplitron II. Los parámetros de PCR han sido optimizados según protocolos estándar con los oligonucleótidos (primers) es-

(a)

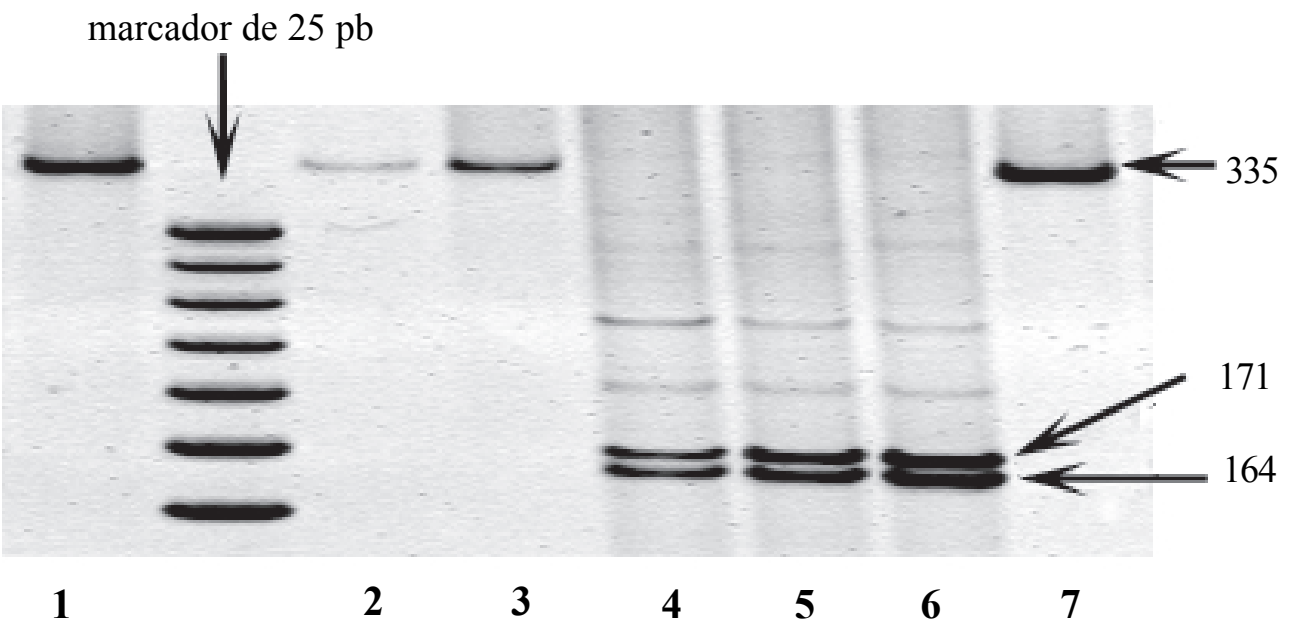

(b)

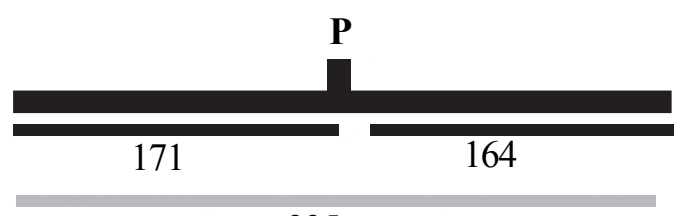

335

Figura 3. Ejemplo de RFLP (restriction fragment length polymorphism) del ADN mitocondrial en el sitio polimórfico 10397. (a) Detección de alelos del RFLP visualizados por electroforesis en geles de poliacrilamida. Un fragmento amplificado por PCR de 335 pares de bases (pb) que contiene el sitio polimórfico es incubado con la enzima de restricción Alu I (secuencia de reconocimiento AGCT). En algunas personas se encuentra el sitio Alu y el fragmento es cortado en dos (171 y 164 $\mathrm{pb})$, muestras 4,5 y 6 . En otras hay mutaciones que destruyen el sitio de reconocimiento Alu I (generalmente mutado a AACC) y la enzima no corta, quedando el fragmento de 335 pb intacto, muestras 1, 2, 3 y 7. (b) Esquema del RFLP mitocondrial 10397. El segmento amplificado de 335 pb con el sitio polimórfico (P), que es cortado en 2 segmentos (171 y 164 pb) si hay un sitio Alu I. Si no hay sitio Alu I, el segmento de 335 pb permanece intacto. 
pecíficos para la amplificación de ADNmt: L635/H708; L5054/H5189; L13257/H13393; 10235-10254/10569-10550; 16287-16306/ 16547-16527 (Sukernik et al., 1996; Merriwether et al., 1996; Easton et al., 1996; Stone \& Stoneking, 1998). Para obtener los patrones de RFLP, los productos PCR fueron digeridos con sus respectivas enzimas de restricción (Fig. 1) según especificaciones del protocolo del fabricante (Corporación Promega). El polimorfismo de la deleción/inserción de 9 pares de bases (Fig. 2) se determina directamente por amplificación PCR con los primers L8215/H8297 (Stone \& Stoneking, 1998). Los productos de PCR y RFLP fueron separados por electroforesis en geles de agarosa $(2 \%)$ y poliacrilamida ( $4 \%)$, teñidos en solución de bromuro de etidio, analizadas con luz UV y registradas digitalmente con fotodocumentador BioDoc Systems, UVP (Fig. 3).

La distribución de frecuencias de subtipos de los haplogrupos ADNmt se indican directamente en porcentajes y para la determinación del índice de diversidad genética $(h)$ se utilizó la fórmula de Nei (1987):

$$
h=\frac{n}{n-1}\left(1-\sum_{i=1}^{k} p_{i}^{2}\right)
$$

$n=$ número de muestras,

$k=$ número de haplotipos,

$p_{i}=$ frecuencia del haplotipo.

\section{Resultados}

\section{Máxima frecuencia de haplotipo B1 y evi- dencia de efecto fundador}

El presente estudio encontró diferencias en la distribución de frecuencias de haplotipos del ADN mitocondrial en las poblaciones de las diferentes islas (Tabla 1). Se observa la predominancia del tipo B1, que es máxima en Taquile (100\%), seguida por Amantaní $(88,6 \%)$, Anapia $(87,5 \%)$ y Los Uros $(75 \%)$. Otros estudios señalan un máximo de $75 \%$ en la frecuencia del haplotipo B1 en poblaciones nativas sudamericanas, incluyendo peruanas
(Merriwether et al., 1996; Rodríguez-Delfín et al, 2001). La comparación entre los índices de diversidad genética de grupos representativos de las cuatro islas revelan una heterogeneidad mayor en Los Uros $(h=0,415)$ que en los pobladores de Anapia $(h=0,239)$ y Amantaní $(h=0,208)$. En cambio, en Taquile se observa una homogeneidad total $(h=0)$. Esto sería evidencia del efecto fundador, es decir de la contribución de un reducido número de individuos ancestrales en la población actual, sobre todo en Taquile.

\section{Distribución de otros alelos}

El haplotipo A2 (17,9\%) ha sido encontrado solamente en las islas Los Uros. La variante C1 está presente en Amantaní (11,4\%) y en Anapia $(4,2 \%)$ y en ésta última, además se observa C2 (4,2\%). El haplotipo D1 se observa tanto en Los Uros $(7,1 \%)$ como en Anapia (4,2\%).

\section{Discusión}

La distribución de las poblaciones nativas actuales obedece a desplazamientos ocurridos durante miles de años en el territorio peruano. Sólo después de la llegada de los españoles tenemos registros de éstos, siendo necesario recurrir a otras fuentes para discernir acerca de las migraciones en la era prehispánica. Elementos antropológicos y sociológicos como la lingüística, las tradiciones culturales y orales nos ayudan a estudiar los orígenes de las diversas etnias.

Actualmente, es posible también establecer patrones genéticos individuales y poblacionales estudiando variantes en el ADN. Así, en estudios de poblaciones modernas y antiguas, las variantes polimórficas en el ADN mitocondrial son bastante usadas para deducir orígenes y desplazamientos de sus ancestros (Merriwether et al., 1996; Lell et al., 2002).

Se han propuesto posibles rutas migratorias para poblar Sudamérica y algunas incluyen dos subgrupos, uno migrando por la costa del Océano Pacífico y poblando las zonas andinas 
(mayormente portadores del haplogrupo $B$ ) y otro por la región Amazónica (en general portadores de haplogrupos $A, C$ y $D$ ) (Greenberg, 1987; Merriwether et al., 1996; RodríguezDelfin et al., 2001). Nuestros resultados sobre el estudio de ADNmt en pobladores de las islas del lago Titicaca concuerdan con la predominancia del subtipo B1 en las poblaciones andinas. Cabe destacar que observamos la frecuencia más alta de B1 que en cualquier estudio previo de poblaciones nativas americanas: en Taquile (100\%), Amantaní (88,6\%), Anapia (87,5\%) y en los Uros (75\%). Por otro lado, en este estudio, la variante A2 (5 de 28 muestras) sólo ha sido encontrada en las islas Los Uros. Esto sugeriría un origen distinto de algunos de sus ancestros de estas islas con respecto a los de Taquile, Amantaní y Anapia. La heterogeneidad en la población de las islas Los Uros sería consecuencia de la mixtura con otros grupos del altiplano, ocurridas desde épocas preincaicas. Así gradualmente, los urus fueron asimilándose al grupo cultural de sus vecinos aymaras. Además, estudios lingüísticos y de grupos sanguíneos indican que los urus, estarían emparentados con la familia lingüística Arawak (diseminados en la selva de Paraguay, regiones de Ucayali-Madre de Dios-Cuzco) y tribus caribeñas, por lo que pertenecerían a un grupo étnico diferente a los aymaras y quechuas (Wachtel, 1986; Torero, 1992).

El grado de parentesco genético entre los cuatro grupos isleños está asociado más a las afinidades lingüísticas que a la cercanía geográfica. Por ejemplo, hay mayor afinidad entre grupos geográficamente alejados como Los Uros-Anapia (ambos aymara hablantes) que entre grupos cercanos como Los Uros-Taquile (aymara y quechua respectivamente).

Así, se encuentra una gran homogeneidad entre los habitantes de las islas Taquile y Amantaní de habla quechua, indicando que genéticamente son afines, acorde con su cercanía geográfica. Las altas frecuencias del subtipo B1 (100\% en Taquile) sugieren que ambas poblaciones descienden de un peque- ño grupo fundador que apareció probablemente en el repoblamiento del siglo XVII.

En cambio, entre los pobladores de las islas Los Uros y Anapia de lengua aymara, hay heterogeneidad que concuerda con los antecedentes históricos de la «aymarización» lingüística de las diferentes etnias del Collao ocurrida desde épocas preincas hasta el final de la colonización española. Existe la hipótesis de que la etnia uru se extinguió de las islas de Los Uros desde hace muchas décadas y que los isleños actuales serían o descenderían de colonos recientes de otras etnias ribereñas (Vellard, 1959; Gran Enciclopedia del Perú, 1998). En contraposición a a esta idea, nosotros creemos que estos isleños todavía conservan un fuerte bagaje genético uru bajo una influencia cultural aymara. Por ejemplo, en esta población hay una alta proporción del alelo $\mathrm{A} 2$ (17,9\%) comparada con $0 \%$ de otras islas (presente estudio), 0\% de poblaciones aymaras de Perú y Chile (Merriwether et al., 1996) ó a 3.7\% de una mezcla de aymaras y quechuas (Rodríguez-Delfín et al., 2001). Por otro lado, cabe notar que A2 se encuentra en mayor proporción en poblaciones amazónicas (de donde se originarían los urus) que en las poblaciones andinas (Rodríguez-Delfín et al., 2001). De manera similar el estudio de las frecuencias del gen $M B L$ (mannose binding lectin) en isleños del lago Titicaca también muestra diferentes proporciones entre los habitantes de la isla de Los Uros y los de las otras islas del lago (Sandoval et al., 2002). Además no se debe descartar un mestizaje de urus con los ribereños en una proporción a determinar en futuros trabajos. La realización de un estudio comparativo con otras poblaciones urus de Bolivia, las ribereñas vecinas en el lago y las de los grupos amazónicos emparentados, serviría para descartar o comprobar la extinción de la etnia $u r u$ del Perú.

En una comparación global, se notan diferencias moderadas entre los pobladores quechua hablantes de Taquile y Amantaní con los pobladores de las islas Los Uros y Anapia 
que hablan aymara, confirmando que una parte de sus ancestros son de origen distinto.

Comparado con estudios en otras poblaciones humanas, podemos afirmar que cada isla todavía mantiene un relativamente alto grado de homogeneidad genética. Esto estaría causado por el establecimiento de un reducido grupo ancestral y por el relativo aislamiento geográfico que ofrecen las islas (efecto fundador). Estudios comparativos de la distribución de frecuencias de haplotipos ADNmt de diversas poblaciones nativas sudamericanas muestran afinidad entre los pobladores de Los Uros y poblaciones amazónicas. Esto concuerda con los estudios lingüísticos y de grupos sanguíneos que sugieren el origen amazónico de los urus (Wachtel, 1986; Torero, 1992).

Los datos históricos, complementados con las particularidades de los marcadores polimórficos de $\mathrm{ADN}$, nos permiten sugerir que los habitantes de las islas Los Uros conservan todavía un importante componente genético uru dentro de su población.

Las diferencias, aunque moderadas, entre los pobladores de las islas Los Uros y Anapia, aymara hablantes, nos indicarían tomar con cautela el uso de las diferencias y semejanzas lingüísticas, ya que serían solamente referencias culturales y no un referente étnico biológico en los estudios genéticos de las poblaciones humanas.

\section{Agradecimientos}

El presente trabajo se dedica a los habitantes del Lago Titicaca, en especial a los escolares de Taquile, Amantaní, Los Uros y Anapia, quienes entusiastamente participaron en el estudio. Agradecemos el cofinanciamiento CONCYTEC (Concurso de Proyectos de Investigación 2000, contrato No. 871-2000-OAL) con la Universidad de San Martín de Porres. Nuestro reconocimiento a los doctores Francisco M. Salzano (Universidade Federal do Rio Grande do Sul, Brasil) y Juan Herrera Carpio (Universidad Nacional del Altiplano, Puno), las autoridades del Hospital Regional MNB, Dirección Regional de Educación, la Capitanía de Puerto de Puno; Concejos Municipales de Mollendo y Puno. A los doctores Armando Guevara y Sonia Guillén, por la valiosa información antropológicohistórico y a todas las personas que de una $\mathrm{u}$ otra manera hicieron posible este estudio.

\section{Literatura citada}

Bouysse-Cassagne, T. 1991. Poblaciones humanas antiguas y actuales. ORSTOM, HISBL, Bolivia, p. 481-498.

Easton R.D.; A.D. Merriwether; D.E. Crews; and R.E. Ferrell 1996. mtDNA Variation in the Yanomami: Evidence for Additional New World Founding Lineages. Am. J. Hum. Genet. 59:213-225.

Espinoza-Avendaño, J. 1989. Taquile. Historia-Economía-Artesanía. Instituto de Investigaciones para el desarrollo social del altiplano. Convenio UNA-NUFFIC, 148 p. Reimpresión,1990 por Talleres IIDSA, Puno.

Fujita, R. 1991. Localisation du gene de l'ataxie de Friedreich par sa liaison génétique et physique avec les loci D9S5 et D9S15. These de Docteur de l'Universite Louis Pasteur de Strasbourg, France, $80 \mathrm{p}$.

Greenberg, J.H. 1987. Language in the Americas. Stanford Univ. Press, Stanford, CA.

Lell, J.T.; R.I. Sukernik; Y.B. Starikovskaya; J.L. Su B; T.G. Schurr; P.A. Underhill and D.C. Wallace. 2002. The Dual Origin and Siberian Affinities of Native American Y Chromosomes. Am. J. Hum. Genet. 70:192-206.

Manelis de Klein, H.E. 1973. Los Urus: El extraño pueblo del altiplano. Estudios Andinos, N7, V3, N1:129-150.

Merriwether, D.A.; W.W. Hall; A. Vahlne and R.E. Ferrell 1996. MtDNA Variation Indicates Mongolia May Have Been the Source for the Founding Population for the New World. Am. J. Hum. Genet. 59:204-212.

Nei, M. 1987. Molecular Evolutionary Genetics. Columbia Univ. Press, New York.

Rodriguez-Delfin, L. A.; V. E. Rubin-de-Celis, M. A. Zago. 2001. Genetic Diversity in an Andean Population from Peru and Regional Migration Patterns of Amerindians in South America: Data from Y Chromosome and Mitochondrial DNA. Hum. Hered 51:97-106.

Sandoval J, Madsen HO, Garred P, Fujita R (2002) Mitochondrial and mannose-binding lectin haplotypes in Quechua and Aymara islanders of the Lake Titicaca. Cold Spring Harbor Symposium «Human Origins and Diseases» Abstracts book. pp. 86 
Simoni L.; F. Calafell; D. Pettener; J. Bertranpetit and G. Barbujani. 2000. Geographic Patterns of mtDNA Diversity in Europe. Am. J. Hum. Genet. V.66:262-278.

Stone, A. and M. Stoneking. 1998. MtDNAAnalysis of a Prehistoric Oneota Population: Implications for the Peopling of the New World. Am. J. Hum. Genet. V62:1153-1170.

Sukernik, R. I.; T. G. Schurr; E. B. Starikovskaya and D. C. Wallace. 1996. Mitochondrial DNA Variation in Native Siberians, with Special Reference to the Evolutionary History of American Indians. Studies on restriction polymorphism. Genetika, T.32, N3:432-439.
Torero, A. 1992. Acerca de la familia lingüística uruquilla (Uru-Chipaya). Revista Andina, N1, Cusco, p. 171-189.

Wachtel, N. 1986. Men of the water: The Uru problem (XVI and XVII centuries). Cambridge University Press \& Editions de la Maison des Sciences de L' Homme, pp.282-310.

Vellard, J. 1959. Poblaciones indígenas del lago Titicaca. Boletín Sociedad Geográfica Lima, 76 (3-4 trimestre): 17-40.

Gran Enciclopedia del Perú. 1998. Editores Lexus, España, p.927. 